2018-05

\title{
Environmental sustainability of light-driven processes for wastewater treatment applications
}

Foteinis, S

http://hdl.handle.net/10026.1/17697

\begin{abstract}
10.1016/j.jclepro.2018.02.038
Journal of Cleaner Production

Elsevier BV
\end{abstract}

All content in PEARL is protected by copyright law. Author manuscripts are made available in accordance with publisher policies. Please cite only the published version using the details provided on the item record or document. In the absence of an open licence (e.g. Creative Commons), permissions for further reuse of content should be sought from the publisher or author. 
1 Environmental sustainability of light-driven processes for wastewater treatment

2

3

4

5

6

7

8

9

10

11

12

13

14

15

16

17

18

19

20

21

22

\section{applications}

Spyros Foteinis ${ }^{\mathrm{a}}$, Alistair G. L. Borthwick ${ }^{\mathrm{b}}$, Zacharias Frontistis $^{\mathrm{c}}$, Dionissios Mantzavinos $^{\mathrm{c}}$, Efthalia Chatzisymeon ${ }^{\mathrm{b} *}$

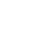

a Senior Engineer, Greek Public Power Corporation (PPC) Renewables S.A., Kapodistriou 3, Ag. Paraskeui, GR-15343, Attica, Greece

${ }^{\mathrm{b}}$ School of Engineering, Institute for Infrastructure and Environment, University of Edinburgh, Edinburgh EH9 3JL, United Kingdom

c Department of Chemical Engineering, University of Patras, Caratheodory 1, University Campus, GR-26504 Patras, Greece

* Corresponding author: e.chatzisymeon@ed.ac.uk, tel.: +44(0)1316505711

\section{Abstract}

A comparative analysis is presented of light-driven advanced oxidation processes in terms of environmental sustainability. Photochemical oxidation has proven a viable option for treating emerging and priority pollutants at laboratory scale. Nevertheless, as a nascent technology, photocatalysis is yet to be widely applied at large-scale water treatment plants. This paper presents a powerful tool that should enable stakeholders to develop sustainable, large-scale, photocatalytic treatment plants by providing knowledge of environmental sustainability and hotspots (where technological flaws 
have high environmental impact) and understanding as to how process sustainability can be improved through scenario analyses. The following processes were examined: natural and simulated solar photolysis, solar photo-Fenton without hydrogen peroxide addition (solar/Fe), solar photo-Fenton (solar/Fe/ $\mathrm{H}_{2} \mathrm{O}_{2}$ ), photolysis under UV-A irradiation (UV-A), titania-mediated photocatalysis (UV-A/ $\left.\mathrm{TiO}_{2}\right)$, photolysis under UV-C irradiation (UV-C), and UV-C treatment with hydrogen peroxide addition (UV$\mathrm{C} / \mathrm{H}_{2} \mathrm{O}_{2}$ ). Actual life cycle inventory data were collected at bench scale, and the environmental performances estimated by means of life cycle assessment. Effective removal of $1 \mu \mathrm{g}$ of $17 \alpha$-ethynylestradiol per liter of wastewater, a commonly occurring micropollutant and endocrine disrupting chemical, was used as the functional unit. Solar photolysis exhibited an environmental footprint about 23 times higher than solar/Fe. Solar $/ \mathrm{Fe} / \mathrm{H}_{2} \mathrm{O}_{2}$ minimized the environmental footprint. Being energy intensive, simulated solar irradiation had a much higher $(\sim 5$-fold $)$ environmental footprint than natural solar light. UV photolysis exhibited low environmental impact, with UV-C found to be about 3 times more environmentally friendly than UV-A photolysis. Addition of $\mathrm{TiO}_{2}$ to UV-A and $\mathrm{H}_{2} \mathrm{O}_{2}$ to UV-C caused their total environmental impacts to decrease by about $97 \%$ and $88 \%$, implying that $\mathrm{UV}-\mathrm{A} / \mathrm{TiO}_{2}$ was better than UV-C/ $\mathrm{H}_{2} \mathrm{O}_{2}$. In terms of total environmental footprint, the AOPs descend in the following order: solar photolysis $>\mathrm{UV}-\mathrm{A}>\mathrm{UV}-\mathrm{C}>$ solar/Fe $>\mathrm{UV}-$ $\mathrm{A} / \mathrm{TiO}_{2}>\mathrm{UV}-\mathrm{C} / \mathrm{H}_{2} \mathrm{O}_{2}>\operatorname{solar} / \mathrm{Fe} / \mathrm{H}_{2} \mathrm{O}_{2}$. The environmental sustainability of all processes was directly proportional to treatment efficiency but inversely proportional to treatment time (due to the large energy input per unit time). Although reagent use (i.e. titania, iron, and hydrogen peroxide) was not associated with high environmental impact, its addition greatly improved process efficiency as well as environmental sustainability. For all examined light-driven processes, the main environmental 
hotspot was electricity consumption. Introduction of renewable energy sources could reduce the environmental footprint of oxidation processes by up to $87.5 \%$.

Keywords: water purification; estrogens; photocatalysis; LCA; EDCs; EE2

\section{Introduction}

Trace- or micro-pollutants are synthetic chemicals of emerging environmental and health concern that have recently been detected in the aquatic environment (Tiedeken, 2017). Several hundred EDCs have been measured in humans and wildlife, even in such remote places as the Arctic (Birnbaum, 2013). There is growing evidence that these pollutants have adverse effects on human health and living organisms. Tracepollutants can act, or have the potential to act, as endocrine-disrupting chemicals (EDCs) that cumulatively interfere with the endocrine system of living organisms and cause genetic abnormalities, infertility, feminization, increased cancer rates, trigger Alzheimer disease, etc. (Rochester, 2013). EDCs derive from the chemical processing industry in the form of drugs, surfactants, cosmetics, and other personal care products, which usually end up in the sewage system. Synthetic estrogens are EDCs that are found in increasing concentrations in natural waters (Zhang et al., 2014) and wastewater (Mohagheghian et al., 2014). A representative synthetic estrogen is $17 \alpha-$ ethynylestradiol (EE2), which is the basic component of the contraceptive pill. EE2 is more stable in an aqueous environment and has greater estrogenic potency $(\sim 11-27$ 
times) than natural estrone (E1) and estradiol (E2). Continuous exposure to EE2, even to concentrations of $\mu \mathrm{g} / \mathrm{L}$, has been found to cause bodyweight loss, accelerate vaginal opening, alter estrous cycles in young animals, and damage fish populations (Frontistis et al., 2015).

Due to their xenobiotic and non-biodegradable nature, conventional biological wastewater treatment plants (WWTPs) cannot effectively remove EDCs, which in turn are discharged into receiving waters. To overcome this, it is necessary to add robust tertiary treatment technologies to existing WWTPs. Of the technologies available for the removal of EDCs, light-driven advanced oxidation processes (AOPs) offer considerable promise. The effectiveness of AOPs is mainly due to the formation of reactive oxygen species (ROS), such as hydroxyl radicals (HO॰), which subsequently oxidize the organic content of water samples. AOPs include solar, UVA and UV-C photolysis and photocatalysis, usually accelerated by adding titania $\left(\mathrm{TiO}_{2}\right)$ (i.e. heterogeneous catalysis) (Lee et al., 2017), hydrogen peroxide $\left(\mathrm{H}_{2} \mathrm{O}_{2}\right)$ and/or iron $\left(\mathrm{Fe}^{2+}\right)$ to form the photo-Fenton reagent (i.e. homogeneous catalysis) (Clarizia et al., 2017). To date, several studies have investigated the treatment of EE2contaminated water by means of UV photocatalysis (Madsen and Søgaard, 2012), UV photolysis (Marinho et al., 2013; Sichel et al., 2011), and solar photocatalysis (Kim et al., 2017; Koutantou et al., 2013). Even so, apart from UV-C photolysis, other lightdriven AOPs are still nascent technologies, not yet applied at industrial-scale.

AOPs are energy intensive, with high operating cost and elevated environmental footprint (Chatzisymeon et al., 2013). Solar photo-Fenton AOPs have high chemical demand, and generate residual fluxes with negative environmental impacts, such as sludge contaminated by metal ions, exhausted solid catalysts, etc. (Rodríguez et al., 2016). Previous research has focused on the degradation efficiency 
and techno-economic feasibility of AOPs, without detailed consideration of environmental sustainability (Rodríguez et al., 2016). A brief review of existing studies on AOPs environmental sustainability is given by (Ioannou-Ttofa et al., 2016).

In order for AOP technology to reach prototype-scale applications, it must be acceptable from an environmental perspective. To achieve this, the environmental sustainability of each AOP should first be assessed at bench- or pilot-scale, in order to identify merits and drawbacks, establish the main environmental impact hotspots, and assess ways of reducing the total environmental footprint through scenario and sensitivity analyses. By determining the optimal environmental performance of AOPs, the technology could be effectively scaled up to sustainable, large-scale applications in water treatment works.

This paper describes a comparative life cycle assessment (LCA) of seven wellestablished light-driven AOPs, namely: solar, solar/Fe, solar $/ \mathrm{Fe} / \mathrm{H}_{2} \mathrm{O}_{2}$, UVA, $\mathrm{UVA} / \mathrm{TiO}_{2}, \mathrm{UVC}$, and $\mathrm{UVC} / \mathrm{H}_{2} \mathrm{O}_{2}$. The aim is to identify the strengths and weaknesses of AOPs from an environmental sustainability perspective, thus enabling process scale up. LCA methodology is employed, in accordance with ISO 14040 and ISO 14044 (ISO, 2006a, b), using SimaPro 8. The assessment was made using life cycle inventory (LCI) data collected from bench-scale experiments, rather than extracted from a database. The results should provide researchers, decision- and policy-makers, and the water treatment industry with a better understanding of the environmental sustainability of light-driven AOPs, which in turn should help advance the technology so that it becomes ready for industrial-scale application. To the best of the authors' knowledge this is the first study to date dealing with LCA of several light-driven oxidation processes. Many publications focus on comparing several irradiation sources in terms of ability to decontaminate/disinfect water and 
wastewater. Assessment of environmental sustainability of such processes, including both solar and UV-irradiated techniques, is presently missing from the literature.

Of the various methodologies used to assess the environmental sustainability of a product or process, the most commonly utilized are multi-criteria analysis (MCA), environmental performance indicators (EPIs), and life cycle assessment (LCA) (Hermann et al., 2007). MCA compares and ranks alternative options, and evaluates environmental consequences according to established criteria. However, its weakness lies in the subjectivity of the weighting step, necessary to evaluate different criteria. EPIs estimate the current or past environmental performance of an organisation and compare it against a set of targets; however, the usefulness of EPIs is limited by insufficient data availability (Hermann et al., 2007). LCA offers an effective means of including environmental considerations in the design, production, use, and disposal of a product (Foteinis et al., 2011). LCA is a tool for the systematic evaluation of environmental impacts, which provides insight into the overall performance and relative contributions of different stages within the product lifespan (Hermann et al., 2007).

\section{Materials and methods}

Data used in the comparative LCA analysis were obtained from laboratory experiments, described by Frontistis et al. (2011, 2012, 2015). All experiments were carried out under the same ambient temperature and water conditions. Table 1 lists the optimum operating conditions assayed for each light-driven process. In all cases, the wastewater sample was stirred by a $50 \mathrm{~W}$ magnetic stirrer and the ambient temperature kept constant at $25 \pm 2{ }^{\circ} \mathrm{C}$. Energy required to keep the temperature 
constant was external to system boundaries, while the stirrer was assumed to operate at $30 \mathrm{~W}$ (i.e. not at full power). At industry scale, wastewater pumping would replace the magnetic stirrer. Simulated solar irradiation was emitted by a Newport, model 96000, $150 \mathrm{~W}$ solar simulator system. The UV-A and UV-C experiments were conducted in an immersion well, batch type, laboratory-scale photoreactor (Ace Glass, Vineland, NJ, USA). UV-A irradiation was provided by a $9 \mathrm{~W}$ lamp (Radium Ralutec, 9W/78, 350-400 nm). UV-C irradiation was provided by an $11 \mathrm{~W}$ lowpressure mercury lamp (Phillips, TUV PL-S). The $\mathrm{Fe}^{2+}$ ionic solution used in the experiments was in the form of $\mathrm{FeSO}_{4} \cdot 7 \mathrm{H}_{2} \mathrm{O}$ ( $\geq 99 \%$, Sigma-Aldrich). $\mathrm{H}_{2} \mathrm{SO}_{4}$ was added in order to regulate the initial water $\mathrm{pH} . \mathrm{TiO}_{2} \mathrm{P} 25$ was donated by Evonik Industries, and $\mathrm{H}_{2} \mathrm{O}_{2}(35 \% \mathrm{w} / \mathrm{w})$ was purchased from Merck.

\section{Environmental sustainability analysis}

To assess the environmental sustainability of light-driven AOPs, LCA methodology was employed, as detailed in ISO 14040 and 14044 (ISO, 2006a, b). Bench-scale experimental results were utilized by the environmental model. The timespan covered 2010 to the present date, the geographical boundaries encompassed Greece and similar countries, and average technology was assumed. For the foreground system, primary inventory data were collected for laboratory-scale experiments, while, for the background system, data were used regarding the most recent average technology (e.g. for electricity the average technology mix in Greece was imported from the ecoinvent database).

\subsection{Functional unit}


The functional unit selected to quantify the performance of a light-driven AOP was the effective removal of $1 \mu \mathrm{g}$ EE2 per liter of treated wastewater. The life cycle inventory (LCI) for each AOP under study was then normalized per functional unit (ISO, 2006a, b) in order to study the environmental performance of the different technologies. Attributional life cycle assessment (ALCA) was used because it estimates the environmental impacts of a product or system according to the delivery of a specified quantity of the functional unit (Chatzisymeon et al., 2016).

\subsection{System boundaries and life cycle inventory (LCI)}

The system boundaries define which unit processes (the smallest elements for which input and output data are quantified in the LCI) are included within the LCA (ISO, 2006a). Energy and raw material requirements, waterborne emissions, and the materials' disposal or recycling are included within system boundaries.

For the solar and UV photoreactor AOPs, LCI data could not be identified and so their primary materials, i.e. glass, lamps, and the stirrer, were taken into account. It was assumed that both photoreactors have similar dimensions and materials, and that all experiments were carried out at the same ambient temperature. Two different scenarios were examined for the solar AOPs. The first scenario comprised the photoreactor and lamp (i.e. simulated solar irradiation), whereas the second scenario did not include the lamp (i.e. natural solar irradiation). The latter scenario is closer to actual operating conditions of solar AOPs. Following Ioannou-Ttofa et al. (2017), the photoreactor glass was assigned a useful lifespan of five years $(10 \mathrm{~h} / \mathrm{d}$ operation, all year round). Recycling was also incorporated. Photoreactor lamps are not included in SimaPro's proprietary life cycle inventory (LCI) databases, and so the LCI data were obtained from relevant literature (Garrett and Collins, 2009; OSRAM, 2016). The 
data were re-scaled according to the power requirements of each process and input to SimaPro in order to simulate the environmental impact of each lamp under study. Data on the stirrer used to mix effluent were not available in SimaPro's proprietary LCI databases, and so were substituted by relevant data concerning the LCI of a lowpower motor (AAB, 2002), re-scaled to fit the rated output of the stirrer under study, and used as input to SimaPro.

Information on the $\mathrm{Fe}^{2+}$ ion as iron sulphate was supplied from the SimaPro LCI databases. Residual $\mathrm{Fe}^{2+}$ in the treated wastewater was also taken into account as waterborne emission. Data on $\mathrm{H}_{2} \mathrm{O}_{2}$ and $\mathrm{H}_{2} \mathrm{SO}_{4}$ reagents were obtained from proprietary LCI databases. Energy used to drive each process was supplied as electricity from the Greek energy grid, which is fossil fuel-dependent and comprises $54 \%$ lignite, $11 \%$ crude oil, $17 \%$ natural gas, and 18\% renewable energy (IoannouTtofa et al., 2016). To carry out the comparative analysis, from an environmental perspective, of light-driven AOPs, the final use and disposal route of treated effluent was taken to be external to system boundaries. In other words, cradle-to-gate (treated effluent) was used.

\section{Table 1.}

\subsection{Life cycle impact assessment (LCIA)}

Life cycle impact assessment (LCIA) relates the data inventory to specific environmental impacts and damages (ISO, 2006a, b). ReCiPe was chosen for the LCIA as a robust method that comprises both midpoint and endpoint impact/damage approaches which examine different stages in the cause-effect chain to calculate 
impact (Chatzisymeon et al., 2016). The endpoint, or damage-oriented, approach translates environmental impacts into issues of concern, such as human health, natural environment, and natural resources. Endpoint results are associated with higher levels of statistical uncertainty, compared to midpoint, due to data gaps and assumptions stacking up along the cause-effect chain, but are easier for decision- and policymakers to comprehend (Chatzisymeon et al., 2016). Given that this is a comparative LCA, results are compared using the following three endpoint damage categories: "Human Health", "Resources", and "Ecosystems". These can be also aggregated into a single score, which makes interpretation simpler.

A hierarchist perspective $(\mathrm{H})$, based on the most common policy principles, was invoked within ReCiPe along with European normalization and average weighting. Decisions whether or not to include information in the $\mathrm{H}$ model are based on mean scientific consensus, and it assumes that, with proper management, environmental impacts can be avoided (Chatzisymeon et al., 2016), thus fitting better the goal and scope of the comparative analysis.

Moreover, in order to ensure accuracy and transparency of the LCA, the primary LCI data along with data used for the background system were verified against information from the open literature (Chatzisymeon et al., 2013; Gimenez et al 2015). Light-driven AOPs comprise a nascent technology for wastewater treatment, and so comparative environmental studies based on similar operating conditions and similar initial organic loads are needed; however, information on these important parameters is scarce.

\subsection{Energy consumption}


The energy consumption of artificial lighting constitutes a major fraction of the

242

243

244 245 calculated from the following equation:

246

247

248

$$
E_{E O}=\frac{P \times t \times 1000}{V \times 60 \times \log \left(C_{i} / C_{f}\right)}
$$

\section{$4 \quad$ Results and discussion}

\section{$\mathrm{H}_{2} \mathrm{O}_{2}$} operating costs in UV treatment. Bolton et al. (2001) introduced the electric energy per order, $E_{E O}$, defined as the energy required for $90 \%$ degradation of a pollutant per $\mathrm{m}^{3}$ of contaminated water. $E_{E O}\left(\mathrm{kWh} / \mathrm{m}^{3} /\right.$ order $)$, for a batch-operated reactor, is

where $P$ is the electrical power of the irradiation source $(\mathrm{kW}), t$ is the irradiation time (min), $V$ is the volume of the treated effluent (L), and $C_{i}$ and $C_{f}$ are the initial and the final pollutant concentrations $(\mathrm{mg} / \mathrm{L})$, respectively.

To render the analysis both comprehensive and straightforward to follow, the results for the solar and UV irradiation light sources are considered separately. Then, a comparative analysis of all processes follows in order to identify the most promising result in terms of environmental sustainability. Finally, a sensitivity analysis is carried out using scenarios to investigate the effect of the main environmental hotspots and to propose "greener" alternatives by which to improve sustainability.

\subsection{Environmental sustainability of solar-driven $\mathrm{AOPs}$ and effects of $\mathrm{Fe}^{2+}$ and}

Results provided by ReCiPe for natural and simulated solar-driven photolysis/photocatalysis at endpoint level (Figure 1) show that simulated (artificial light) and natural solar photolysis yielded by far the highest environmental footprints of $\sim 11 \mathrm{mPt}$ and $\sim 2 \mathrm{mPt}$ per functional unit, respectively. The environmental footprint 
due to photolysis was $\sim 23$ times larger than that of simulated/natural solar/Fe, using low reagent concentration $\left(5 \mathrm{mg} / \mathrm{L} \mathrm{Fe}^{2+}\right.$ ), with scores of $0.477 \mathrm{mPt}$ (artificial light) and $0.089 \mathrm{mPt}$ (natural light). For photolysis, as well as all other AOPs, the main environmental hotspot was electricity use derived from Greece's fossil fuel-dependent electricity mix. At the time of writing, electricity systems worldwide use fossil fuels for bulk power generation (Berill et al., 2016) and so the foregoing results are presently valid for Greece, Europe and beyond. Indirect impacts of the use of electricity from fossil fuels can be traced mainly to the "Human Health" damage category, followed by "Resources", and less so the "Ecosystem" (Chatzisymeon et al., 2016). "Human Health" damage is affected by fossil-fuel mining and combustion, which release toxic materials including metals, sulphur, and polycyclic aromatic hydrocarbons (PAHs) to the environment (Chatzisymeon et al., 2016). Fossil-fuel extraction and burning contribute to climate change. Natural gas extraction also releases $\mathrm{SO}_{2}$. Impacts from coal arise from tailpipe emissions after combustion and emissions during blasting at coal mines (Berill et al., 2016). "Resources" damage is primarily caused by depletion of fossil fuels for electricity generation and of mineral resources used to construct equipment required for resource extraction, processing and consumption, and to a lesser degree by equipment related to AOPs (i.e. the stirrer and photoreactor). Turning to "Ecosystem" damage, phosphate leachate from coal mining spoil landfill sites and the emission of nitrogen oxides from combustion of fossil-fuel directly impact on acidification and eutrophication. Waterborne metal emissions from coal power plants, natural gas extraction (particularly of bromine) and from disposed coal mine spoil (nickel and magnesium) affect ecotoxicity (Berill et al., 2016; Ioannou-Ttofa et al., 2016). 

environmental footprint of simulated solar photolysis and photocatalysis is about a factor of 5 higher than natural solar light. This is attributed to electricity consumption by the lamp ( $\sim 81.3 \%$ of total environmental footprint), and to a much lower degree to 292 the lamp material ( $\sim 0.05 \%$ of total environmental footprint). In terms of material, the stirrer (i.e. motor) contributed $12.4 \%$ and $2.3 \%$ to the total environmental footprints for natural and simulated solar photolysis. Finally, the photoreactor material (glass) made a very low contribution to the total environmental footprint, $0.257 \%$ and 0.0494\% for natural and simulated solar photolysis, respectively, mainly because of 297 the long lifespan of glass whose recycling was included in the system boundaries. The relatively high environmental footprint of solar photolysis is due to its low treatment efficiency as it consumes energy during the stirring process while EE2 is removed from wastewater.

Figure 1.

To study the environmental impacts of the more environmentally friendly natural solar-driven AOPs, a separate comparison was undertaken, neglecting photolysis and simulated solar irridiation. Figure 2 shows that the amount of oxidation reagents used strongly affected the environmental sustainability of solar-driven AOPs, with high reagent concentration improving the overall environmental sustainability of solar AOPs. At low concentration of iron ions $\left(5 \mathrm{mg} / \mathrm{L} \mathrm{Fe}^{2+}\right)$ the total evironmental footprint of natural solar/Fe was estimated to be $0.089 \mathrm{mPt}$, whereas when the concentration was increased to $15 \mathrm{mg} / \mathrm{L}$ the total environmental footprint reduced by 
about half to $0.047 \mathrm{mPt}$ per functional unit (Figure 2). When $\mathrm{H}_{2} \mathrm{O}_{2}$ was also added as a reagent, the environmental sustainability of the process was further enhanced. More specifically, when keeping the iron ion concentration constant at $5 \mathrm{mg} / \mathrm{L}$ and adding $10 \mathrm{mg} / \mathrm{L} \mathrm{H}_{2} \mathrm{O}_{2}$ the total environmental footprint of the process was $\sim 0.01 \mathrm{mPt}$ per functional unit, and by increasing the $\mathrm{H}_{2} \mathrm{O}_{2}$ concentration to $17.2 \mathrm{mg} / \mathrm{L}$ the environmental footprint of the process achieved a minumum of $\sim 0.356 \times 10^{-3} \mathrm{mPt}$ per functional unit.

This large reduction is attributed to: (a) increased degradation efficiency at higher $\mathrm{H}_{2} \mathrm{O}_{2}$ concentration (Table 1); (b) lower treatment time (15 min for $10 \mathrm{mg} / \mathrm{L}$ $\mathrm{H}_{2} \mathrm{O}_{2}$, and $1 \mathrm{~min}$ for $17.2 \mathrm{mg} / \mathrm{L} \mathrm{H}_{2} \mathrm{O}_{2}$ ) and hence reduced energy consumption; and (c) use of low amounts of $\mathrm{H}_{2} \mathrm{O}_{2}$, a non-toxic chemical without elevated environmental impact. As mentioned before, the environmental impacts of solar/Fe can be traced back to Greece's fossil fuel-dependent electricity mix used to drive the stirrer. The contributions of electricity consumption to the total environmental footprint of natural solar/Fe (5 mg/L and $15 \mathrm{mg} / \mathrm{L})$, natural solar/Fe/ $\mathrm{H}_{2} \mathrm{O}_{2}(10 \mathrm{mg} / \mathrm{L})$ and natural solar $/ \mathrm{Fe} / \mathrm{H}_{2} \mathrm{O}_{2}(17.2 \mathrm{mg} / \mathrm{L})$ were $87.4 \%, 87.3 \%$ and $86.5 \%$. The photoreactor and the stirrer-drive motor made material contributions of $0.256 \pm 0.02 \%$ and $12.35 \pm 0.05$ $\%$. As a non-hazardous reagent when in small concentrations, $\mathrm{Fe}^{2+}$ had a negligible effect in all cases (its biggest score was $0.058 \%$ in natural solar/ $/ \mathrm{Fe} / \mathrm{H}_{2} \mathrm{O}_{2}(17.2$ $\mathrm{mg} / \mathrm{L})$ ). Similarly, the addition of miniscule amounts of $\mathrm{H}_{2} \mathrm{SO}_{4}$ in concentrations of about $50 \mu \mathrm{L} / \mathrm{L}$ led to it also making a negligible contribution. For natural solar/Fe/ $/ \mathrm{H}_{2} \mathrm{O}_{2}$, addition of hydrogen peroxide at concentrations of $10 \mathrm{mg} / \mathrm{L}$ and 17.2 $\mathrm{mg} / \mathrm{L}$ contributed $\sim 0.037 \%$ and $0.943 \%$ to total environmental footprint. The latter, higher percentage contribution is related to the overall low environmental footprint of the process $\left(0.356 \times 10^{-3} \mathrm{mPt}\right)$ and the higher quantity of hydrogen peroxide used (and 
the knock-on increased energy and materials required for its synthesis). It should be noted that no $\mathrm{H}_{2} \mathrm{O}_{2}$ emissions (e.g. airborne, waterborne) or harmful by-products were assumed to be generated during treatment.

Figure 2.

\subsection{Environmental sustainability of UV-A and UV-C photocatalysis}

Figure 3 presents the environmental footprints of UV-A and UV-C photolysis/photocatalysis in terms of "Human Health", "Resources" and "Ecosystems" endpoint damage categories. UV-A photolysis yields a higher environmental footprint $(0.309 \mathrm{mPt})$, whereas that of UV-C is about a factor of three smaller $(0.117 \mathrm{mPt})$. This is expected because UV-C treatment has a much higher treatment efficiency due to the higher energy (Frontistis et al., 2015), compared to UV-A treatment. In both cases the lamp materials hardly contributed to the total environmental footprint, whereas the UV-C lamp required about $20 \%$ higher power but also had significantly higher treatment efficiency (see Table 1). As a result, UV-C removed $1 \mu \mathrm{g} / \mathrm{L}$ of EE2 at a much faster rate than UV-A treatment, requiring less energy and contributing less environmental footprint per functional unit.

When reagents were added, the environmental footprint of both UV-A and UV-C treatment was substantially reduced. Figure 3 shows that addition of titania (10 $\mathrm{mg} / \mathrm{L} \mathrm{TiO}_{2}$ ) drastically reduced the total environmental footprint of UV-A treatment, from $\sim 309 \mu \mathrm{Pt}$ for UV-A photolysis to $\sim 9.2 \mu \mathrm{Pt}$ for $\mathrm{UV}-\mathrm{A} / \mathrm{TiO}_{2}$ heterogenous photocatalysis. As far as UV-C treatment is concerned, the addition of $\mathrm{H}_{2} \mathrm{O}_{2}(10$ $\mathrm{mg} / \mathrm{L}$ ) also had a profound effect, with the environmental footprint of UV-C 
361 photolysis reducing from $\sim 117 \mu \mathrm{Pt}$ for $\mathrm{UV}-\mathrm{C}$ to $\sim 13.8 \mu \mathrm{Pt}$ for $\mathrm{UV}-\mathrm{C} / \mathrm{H}_{2} \mathrm{O}_{2}$. These 362 large reductions ( $\sim 97 \%$ for $\mathrm{UV}-\mathrm{A} / \mathrm{TiO}_{2}$ and $\sim 88 \%$ for $\mathrm{UV}-\mathrm{C} / \mathrm{H}_{2} \mathrm{O}_{2}$ ) are due to a 363 combination of improved treatment efficiency and reduced treatment time (Table 1).

As with solar-driven AOPs, the environmental sustainability of UV-driven AOPs is enhanced by addition of small amounts of the non-hazardous reagents, $\mathrm{TiO}_{2}$ and $\mathrm{H}_{2} \mathrm{O}_{2}$, leading to significant improvement in degradation efficiency and reduction in treatment time, especially for UV-A treatment.

Electricity consumption makes the largest contribution to most damage categories, reflected by its contribution to the total environmental footpint of UVdriven AOPs of $88.3 \pm 0.1 \%$. This score is dominated by electricity consumption by the stirrer motor and, to a lesser degree, to the lamp(s). The stirrer motor as a material was the next most important environmental hotspot with scores ranging from $9.15 \%$ to $9.63 \%$ of the total environmental footpint. The lamp as a material contributed from $1.79 \%$ for UV-A to $2.35 \%$ for UV-C. The photoreactor as a material (glass) contributed from $0.19 \%$ for UV-C to $0.29 \%$ for UV-A. The reagents $\mathrm{TiO}_{2}$ and $\mathrm{H}_{2} \mathrm{O}_{2}$ contributed very low percentages, $0.236 \%$ for $\mathrm{UV}-\mathrm{A} / \mathrm{TiO}_{2}$ and $0.0273 \%$ for UV$\mathrm{C} / \mathrm{H}_{2} \mathrm{O}_{2}$, of the total environmental footprint. Even though $\mathrm{TiO}_{2}$ had a higher impact than $\mathrm{H}_{2} \mathrm{O}_{2}, \mathrm{UV}-\mathrm{C} / \mathrm{H}_{2} \mathrm{O}_{2}$ exhibited a slightly higher total environmental footprint than $\mathrm{UV}-\mathrm{A} / \mathrm{TiO}_{2}$, mainly due to the reduced treatment time of the latter (Table 1).

\section{Figure 3.}

\subsection{Environmental sustainability of solar versus UV-A and UV-C photocatalysis}


Given that photolysis invariably exhibited the highest overall environmental footprint, the most promising photocatalytic processes were determined in terms of environmental sustainability. Figure 4 presents a comparative analysis, using ReCiPe impact assessment method, of natural solar/Fe, natural solar/Fe/ $/ \mathrm{H}_{2} \mathrm{O}_{2}, \mathrm{UV}-\mathrm{A} / \mathrm{TiO}_{2}$ and $\mathrm{UV}-\mathrm{C} / \mathrm{H}_{2} \mathrm{O}_{2}$ photocatalysis. Natural solar $/ \mathrm{Fe} / \mathrm{H}_{2} \mathrm{O}_{2}$, at high reagent concentrations $\left(\mathrm{Fe}^{2+}=5 \mathrm{mg} / \mathrm{L}\right.$ and $\left.\mathrm{H}_{2} \mathrm{O}_{2}=17.2 \mathrm{mg} / \mathrm{L}\right)$ yielded the lowest score $(0.356 \mu \mathrm{Pt}$ per functional unit) amongst all processes. For simulated solar irradiation, the total environmental footprint of solar/ $\mathrm{Fe} / \mathrm{H}_{2} \mathrm{O}_{2}$ rose to $1.869 \mu \mathrm{Pt}$, but nevertheless remains substantially lower than all the other light-driven AOPs considered. Again, the presence of iron and hydrogen peroxide oxidants, the reduced treatment time and enhanced EE2 removal efficiency caused the energy demand per functional unit to be minimized, lowering the environmental footprint. The next most environmentally friendly $\mathrm{AOPs}$ were $\mathrm{UV}-\mathrm{A} / \mathrm{TiO}_{2} \quad(\sim 9.2 \mu \mathrm{Pt}$ or $\sim 96 \%$ higher than natural solar $\left./ \mathrm{Fe} / \mathrm{H}_{2} \mathrm{O}_{2}\right)$ and $\mathrm{UV}-\mathrm{C} / \mathrm{H}_{2} \mathrm{O}_{2}(\sim 13.8 \mu \mathrm{Pt})$. Both exhibited relatively high treatment efficiency, with $\mathrm{UV}-\mathrm{A} / \mathrm{TiO}_{2}$ requiring less treatment time to achieve EE2 removal (Table 1), which meant less energy input and a lower environmental footprint than $\mathrm{UV}-\mathrm{C} / \mathrm{H}_{2} \mathrm{O}_{2}$. Also, the lamp required higher energy to drive the $\mathrm{UV}-\mathrm{C} / \mathrm{H}_{2} \mathrm{O}_{2}$ process (11W) than UV-A/TiO $2(9 \mathrm{~W})$. The lamps, photoreactor, and stirrer made low contributions as materials to the total environmental footprints of the UV-C/ $\mathrm{H}_{2} \mathrm{O}_{2}$ and $\mathrm{UV}-\mathrm{A} / \mathrm{TiO}_{2}$ processes. The contribution by the reagents, $\mathrm{TiO}_{2}$ and $\mathrm{H}_{2} \mathrm{O}_{2}$, was miniscule compared to electricity consumption. Finally, natural solar/Fe exhibited a high overall environmental footprint, especially at low reagent concentration $(5 \mathrm{mg} / \mathrm{L}$ $\mathrm{Fe}^{2+}$ ) where the value was $0.089 \mathrm{mPt}$. For a high iron concentration (i.e. $15 \mathrm{mg} / \mathrm{L}$ ), the total environmental footprint was halved, to $0.047 \mathrm{mPt}$ per functional unit (Figures 2 and 4). 

same environmental hotspot, namely electricity consumption from Greece's fossil fuel-dependent energy mix, which dominated the contributions to ReCiPe's damage 412 categories "Human Health" and "Resources". Similar findings were obtained by 413 (Chatzisymeon et al., 2013) who compared the environmental sustainability of UV$414 \mathrm{~A} / \mathrm{TiO}_{2}$ with electrochemical and wet air oxidation processes for treatment of agro415 industrial wastewater.

Figure 4.

The present comparison is based on bench-scale experimental data. It is expected that further benefits can be achieved for all AOPs examined, in terms of lowering the environmental footprint per functional unit when the processes are scaled up. For example, in prototype applications, the stirring processes, which required large energy

423 inputs at bench scale, will be replaced by pumping which is more energy efficient. 424 Given that it also consumes electricity, pumping is likely to be a prime environmental 425 hotspot (as also suggested by Foteinis et al. (2018) in a study of pilot-scale Fenton processes for pharmaceutical wastewater treatment).

427 Energy consumption to degrade $90 \%$ of EE2 was also estimated in order to undertake 428 a more comprehensive comparative analysis of artificial light-driven oxidation 429 processes. The corresponding treatment time was estimated either using experimental 430 values from photocatalytic tests carried out by Frontistis et al. (2015), Frontistis et al. 431 (2012) and Frontistis et al. (2011) or by extrapolating the experimental values to 432 achieve 90\% removal of EE2. The results are shown in Table 2, where it is observed 
that $\mathrm{UVA} / \mathrm{TiO}_{2}$ process has the lowest energy demands followed by $\mathrm{UVC} / \mathrm{H}_{2} \mathrm{O}_{2}$, solar/Fe(5mg/L)/ $\mathrm{H}_{2} \mathrm{O}_{2}, \quad$ UVC, UVA, solar/Fe(15mg/L), solar/Fe(5mg/L) and simulated solar process. In principle, these results are consistent with those obtained from LCA (Figure 4) confirming the high dependence of AOPs on electricity consumption.

\section{Table 2.}

\subsection{Sensitivity analysis}

The main environmental barrier to light-driven AOPs under study is electricity consumption from the Greek energy mix dominated by fossil fuels. Power systems based largely on renewable energy sources (RES) perform much better regarding climate change and other impact categories than systems based on fossil fuels (Berrill et al., 2016). A sensitivity analysis was carried out involving three energy mix scenarios solely based on RES, i.e. solar, wind, and hydropower, all naturally abundant in Greece, Europe and beyond. Energy storage, curtailment, and grid extension were neglected because the aim of scenario analysis is purely to illustrate possible pathways and futures, rather than make forecasts or predictions (Kouloumpis et al., 2015). Moreover, the extra impacts caused by energy storage and grid extension are likely to be of such relatively small magnitude that the environmental benefits of switching to renewables would not be undermined (Berrill et al., 2016). The use of RES to meet the electricity needs of light-driven AOPs is expected to lead to substantial improvement in their environmental sustainability. For example, use of an electricity mix solely based on photovoltaic (PV) systems (i.e. $3 \mathrm{kWp}$ single-Si panels 
mounted on slanted roofs) decreases the total environmental footprint of solar AOPs by about $85 \%$ and UV-driven AOPs by $87 \%$. On the other hand, use of an electricity mix solely based on wind energy (onshore wind turbines, capacity in the range from 1 to $3 \mathrm{MW}$ ) further improves the environmental sustainability of light-driven AOPs because energy from wind turbines usually has a lower environmental impact than solar PVs (Chatzisymeon et al., 2016). In this case, the total environmental footprint of solar AOPs and UV-driven AOPs is decreased by about $81 \%$ compared to the initial scenario. Finally, use of an electricity mix solely based on hydropower leads to the largest decrease in total environmental footprint of light-driven AOPs by $86 \%$ (solar) and $87 \%$ (UV) because hydropower is the most environmentally friendly RES option (Ioannou-Ttofa et al., 2016).

In all cases, the highest reduction in environmental footprint occurred for the most energy intensive AOPs (i.e. simulated solar, UV-A, and UV-C, ordered from higher to lower reduction), whereas the smallest reduction occurred for the most energy efficient AOPs (i.e. solar/ $/ \mathrm{Fe} / \mathrm{H}_{2} \mathrm{O}_{2}$, solar/Fe, UV-A/TiO 2 , and $\mathrm{UV}-\mathrm{C} / \mathrm{H}_{2} \mathrm{O}_{2}$, ordered from lower to higher reduction). The order of light-driven processes in terms of environmental sustainability remained the same for all scenarios; from higher to lower score: natural or simulated solar $>$ UV-A $>$ UV-C $>$ natural or simulated solar/Fe $>\mathrm{UV}-\mathrm{A} / \mathrm{TiO}_{2}>\mathrm{UV}-\mathrm{C} / \mathrm{H}_{2} \mathrm{O}_{2}>$ natural or simulated solar $/ \mathrm{Fe} / \mathrm{H}_{2} \mathrm{O}_{2}$. Even so, it should be noted that $\mathrm{UV}-\mathrm{A} / \mathrm{TiO}{ }_{2}$ and $\mathrm{UV}-\mathrm{C} / \mathrm{H}_{2} \mathrm{O}_{2}$ exhibited similar environmental footprints when using RES.

\section{Conclusions}


480 This paper has investigated the environmental performance of light-driven AOPs at 481 removing an endocrine disruptor, EE2, from wastewater using actual life cycle 482 inventory (LCI) data. It was found that the environmental sustainability of light483 driven AOPs was directly proportional to treatment efficiency (which was expected 484 given that the chosen functional unit was the removal of $1 \mu \mathrm{g}$ EE2 per liter of 485 wastewater), and was also inversely proportional to treatment time. Moreover, 486 electricity consumption from the fossil fuel-dependent Greek energy mix was the 487 main environmental hotspot for all examined AOPs. The $\mathrm{Fe}^{2+}, \mathrm{H}_{2} \mathrm{O}_{2}$, and $\mathrm{H}_{2} \mathrm{SO}_{4}$ 488 reagents used in light-driven AOPs were associated with low environmental impacts 489 because the chemicals did not detrimentally affect health or the eco-system, no 490 harmful by-products were generated, and only low dosages were used. Use of RES to 491 meet the electricity needs of light-driven AOPs substantially improved their 492 environmental sustainability, by up to $87 \%$ for solar- and $88 \%$ for UV-driven AOPs. 
$A A B, 2002$. Environmental Product Declaration For Electric Motor Type $90 \mathrm{~S} 4$ Pole

Birnbaum, L.S., 2013. State of the Science of Endocrine Disruptors. Environmental Health Perspectives 121, a107-a107.

Chatzisymeon, E., Foteinis, S., Borthwick, A.G.L., 2016. Life cycle assessment of the environmental performance of conventional and organic methods of open field pepper cultivation system. The International Journal of Life Cycle Assessment, 1-13.

Chatzisymeon, E., Foteinis, S., Mantzavinos, D., Tsoutsos, T., 2013. Life cycle assessment of advanced oxidation processes for olive mill wastewater treatment. Journal of Cleaner Production 54, 229-234.

Foteinis, S., Kouloumpis, V., Tsoutsos, T., 2011. Life cycle analysis for bioethanol production from sugar beet crops in Greece. Energy Policy 39, 4834-4841.

Frontistis, Z., Daskalaki, V.M., Hapeshi, E., Drosou, C., Fatta-Kassinos, D., Xekoukoulotakis, N.P., Mantzavinos, D., 2012. Photocatalytic (UV-A/TiO2) degradation of $17 \alpha$-ethynylestradiol in environmental matrices: Experimental studies and artificial neural network modeling. Journal of Photochemistry and Photobiology A: Chemistry 240, 33-41.

Frontistis, Z., Kouramanos, M., Moraitis, S., Chatzisymeon, E., Hapeshi, E., Fatta-Kassinos, D., Xekoukoulotakis, N.P., Mantzavinos, D., 2015. UV and simulated solar photodegradation of $17 \alpha$-ethynylestradiol in secondary-treated wastewater by hydrogen peroxide or iron addition. Catalysis Today 252, 84-92.

Frontistis, Z., Xekoukoulotakis, N.P., Hapeshi, E., Venieri, D., Fatta-Kassinos, D., Mantzavinos, D., 2011. Fast degradation of estrogen hormones in environmental matrices by photoFenton oxidation under simulated solar radiation. Chemical Engineering Journal 178, 175182.

Garrett, P., Collins, M., 2009. Life Cycle Assessment of Product Stewardship Options for Mercury Containing Lamps in New Zealand: Final Report. Environmental Resources Management (ERM), Ministry for the Environment, New Zealand.

Hermann, B.G., Kroeze, C., Jawjit, W., 2007. Assessing environmental performance by combining life cycle assessment, multi-criteria analysis and environmental performance indicators. Journal of Cleaner Production 15, 1787-1796.

Ioannou-Ttofa, L., Foteinis, S., Chatzisymeon, E., Michael-Kordatou, I., Fatta-Kassinos, D., 2016. Life cycle assessment of solar-driven oxidation as a polishing step of secondary-treated urban effluents. Journal of Chemical Technology \& Biotechnology, n/a-n/a.

ISO, 2006a. ISO 14040:2006 - Environmental management -- Life cycle assessment -Principles and framework. International Organization for Standardization, Geneva, Switzerland (2006).

ISO, 2006b. ISO 14044:2006 - Environmental management -- Life cycle assessment -Requirements and guidelines. International Organization for Standardization, Geneva, Switzerland (2006).

Kouloumpis, V., Stamford, L., Azapagic, A., 2015. Decarbonising electricity supply: Is climate change mitigation going to be carried out at the expense of other environmental impacts? Sustainable Production and Consumption 1, 1-21.

Mohagheghian, A., Nabizadeh, R., Mesdghinia, A., Rastkari, N., Mahvi, A.H., Alimohammadi, M., Yunesian, M., Ahmadkhaniha, R., Nazmara, S., 2014. Distribution of estrogenic steroids in municipal wastewater treatment plants in Tehran, Iran. Journal of Environmental Health Science and Engineering 12, 97-97.

OSRAM, 2016. Life cycle analysis of OSRAM products. OSRAM GmbH,, Hellabrunner Straße 1, D-81543 München, Deutschland. 
543 Rochester, J.R., 2013. Bisphenol A and human health: A review of the literature. 544 Reproductive Toxicology 42, 132-155.

545 Rodríguez, R., Espada, J.J., Pariente, M.I., Melero, J.A., Martínez, F., Molina, R., 2016. 546 Comparative life cycle assessment (LCA) study of heterogeneous and homogenous Fenton 547 processes for the treatment of pharmaceutical wastewater. Journal of Cleaner Production 548 124, 21-29.

549 Tiedeken, E.J., Tahar, A., McHugh, B., Rowan, N.J., 2017. Monitoring, sources, receptors, and 550 control measures for three European Union watch list substances of emerging concern in 551 receiving waters - A 20 year systematic review. Science of The Total Environment 574, 11405521163.

553 Zhang, Z., Ren, N., Kannan, K., Nan, J., Liu, L., Ma, W., Qi, H., Li, Y., 2014. Occurrence of 554 endocrine-disrupting phenols and estrogens in water and sediment of the Songhua river, 555 northeastern China. Archives of environmental contamination and toxicology 66, 361-369. 
560 Table 1: Experimental data, taken from Frontistis et al. (2011, 2012, 2015), used to 561 build the LCI of light-driven AOPs.

562 Table 2: Electrical energy $\left(\mathrm{E}_{\mathrm{EO}}\right)$ consumed by several light-driven oxidation 563 processes. 
Table 1.

\begin{tabular}{|c|c|c|c|c|c|c|c|c|}
\hline $\begin{array}{l}\text { Light-driven } \\
\text { process }\end{array}$ & $\begin{array}{l}\text { Irradiation } \\
\text { power, W }\end{array}$ & $\begin{array}{l}{\left[\mathrm{TiO}_{2}\right]} \\
\mathrm{mg} / \mathrm{L}\end{array}$ & $\begin{array}{l}\text { Power for } \\
\text { water } \\
\text { stirring, } \\
\text { W } \\
\end{array}$ & $\begin{array}{l}{\left[\mathrm{Fe}^{2+}\right]} \\
\mathrm{mg} / \mathrm{L}\end{array}$ & $\begin{array}{l}\mathrm{H}_{2} \mathrm{O}_{2} \\
\mathrm{mg} / \mathrm{L}\end{array}$ & $\begin{array}{l}\text { Treatment } \\
\text { time, min }\end{array}$ & $\begin{array}{l}\text { EE2 } \\
\text { removal, } \\
\mu \mathrm{g} / \mathrm{L}\end{array}$ & Reference \\
\hline Solar & 150 & - & 30 & - & - & 60 & 2 & $\begin{array}{l}\text { (Frontistis et } \\
\text { al., 2015) }\end{array}$ \\
\hline \multirow{2}{*}{ Solar/Fe } & 150 & - & 30 & 5 & - & 60 & 46 & $\begin{array}{l}\text { (Frontistis et } \\
\text { al., 2015) }\end{array}$ \\
\hline & 150 & - & 30 & 15 & - & 60 & 86 & $\begin{array}{l}\text { (Frontistis et } \\
\text { al., 2015) }\end{array}$ \\
\hline \multirow{2}{*}{$\mathrm{Solar} / \mathrm{Fe} / \mathrm{H}_{2} \mathrm{O}_{2}$} & 150 & - & 30 & 5 & 10 & 15 & 98 & $\begin{array}{l}\text { (Frontistis et } \\
\text { al., 2015) }\end{array}$ \\
\hline & 150 & - & 30 & 5 & 17.2 & 1 & 196 & $\begin{array}{l}\text { (Frontistis et } \\
\text { al., 2011) }\end{array}$ \\
\hline UVA & 9 & - & 30 & - & - & 60 & 17 & $\begin{array}{l}\text { (Frontistis et } \\
\text { al., 2015) }\end{array}$ \\
\hline $\mathrm{UVA} / \mathrm{TiO}_{2}$ & 9 & 750 & 30 & - & - & 10 & 95 & $\begin{array}{l}\text { (Frontistis et } \\
\text { al., 2012) }\end{array}$ \\
\hline UVC & 11 & - & 30 & - & - & 60 & 47 & $\begin{array}{l}\text { (Frontistis et } \\
\text { al., 2015) }\end{array}$ \\
\hline $\mathrm{UVC} / \mathrm{H}_{2} \mathrm{O}_{2}$ & 11 & - & 30 & - & 10 & 15 & 100 & $\begin{array}{l}\text { (Frontistis et } \\
\text { al., 2015) }\end{array}$ \\
\hline
\end{tabular}

\begin{tabular}{|c|c|c|c|c|c|}
\hline Light-driven process & $\begin{array}{l}\text { Irradiation } \\
\text { power, } \mathrm{kW}\end{array}$ & $\begin{array}{c}\text { Volume, } \\
\text { L }\end{array}$ & $\begin{array}{l}\text { Treatment time to remove } \\
90 \% \text { of EE2, } \min \end{array}$ & $\begin{array}{c}E_{E O}, \\
\mathrm{kWh} / \mathrm{m}^{3} / \text { order } \\
\end{array}$ & Reference \\
\hline Solar & 0.150 & 0.3 & 2251 & 18758 & $\begin{array}{l}\text { (Frontistis } \\
\text { et al., 2015) }\end{array}$ \\
\hline Solar $/ F e(5 m g / L)$ & 0.150 & 0.3 & 115 & 958 & $\begin{array}{l}\text { (Frontistis } \\
\text { et al., 2015) }\end{array}$ \\
\hline Solar/Fe(15mg/L) & 0.150 & 0.3 & 70 & 583 & $\begin{array}{l}\text { (Frontistis } \\
\text { et al., 2015) }\end{array}$ \\
\hline $\operatorname{Solar} / \mathrm{Fe}(5 \mathrm{mg} / \mathrm{L}) / \mathrm{H}_{2} \mathrm{O}_{2}$ & 0.150 & 0.3 & 2 & 17 & $\begin{array}{l}\text { (Frontistis } \\
\text { et al., 2015) }\end{array}$ \\
\hline UVA & 0.009 & 0.3 & 312 & 156 & $\begin{array}{l}\text { (Frontistis } \\
\text { et al., 2015) }\end{array}$ \\
\hline UVA/TiO 2 & 0.009 & 0.3 & 7 & 4 & $\begin{array}{l}\text { (Frontistis } \\
\text { et al., 2012) }\end{array}$ \\
\hline UVC & 0.011 & 0.3 & 113 & 69 & $\begin{array}{l}\text { (Frontistis } \\
\text { et al., 2015) }\end{array}$ \\
\hline $\mathrm{UVC} / \mathrm{H}_{2} \mathrm{O}_{2}$ & 0.011 & 0.3 & 10 & 6 & $\begin{array}{l}\text { (Frontistis } \\
\text { et al., 2015) }\end{array}$ \\
\hline
\end{tabular}


571 Figure 1. Environmental footprint of natural and simulated solar (a) photolysis and (b)

572 photocatalysis per functional unit, i.e. removal of $1 \mu \mathrm{g}$ EE2 per liter of wastewater.

573 Figure 2. Environmental footprint of natural solar photocatalysis for removal of $1 \mu \mathrm{g}$ 574 EE2 per liter of wastewater. Inset: environmental footprint of natural solar/Fe/H2O2 $575 \quad(17.2 \mathrm{mg} / \mathrm{L})$.

576 Figure 3. Environmental footprint of UV-A and UV-C AOPs per functional unit 577 (removal of $1 \mu \mathrm{g}$ EE2 per liter of wastewater).

578 Figure 4. Environmental footprint of natural solar, UV-A and UV-C photocatalysis 579 for removal of $1 \mu \mathrm{g}$ EE2 per liter of wastewater.

580

581 


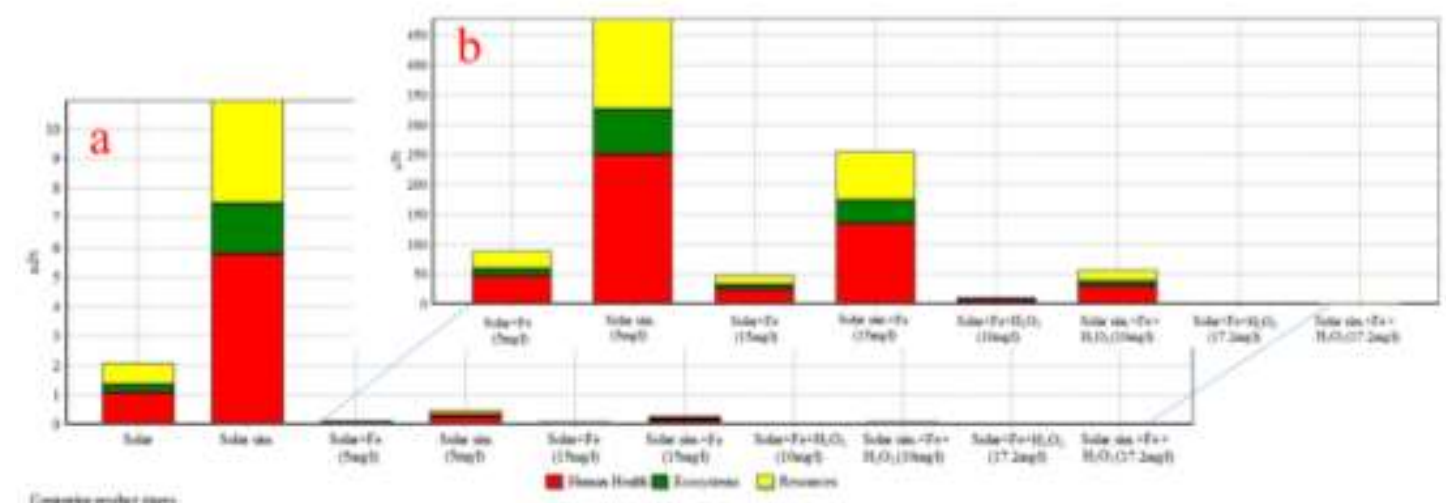

583

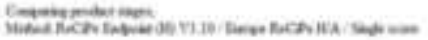

584 Figure 1.

585

586

587

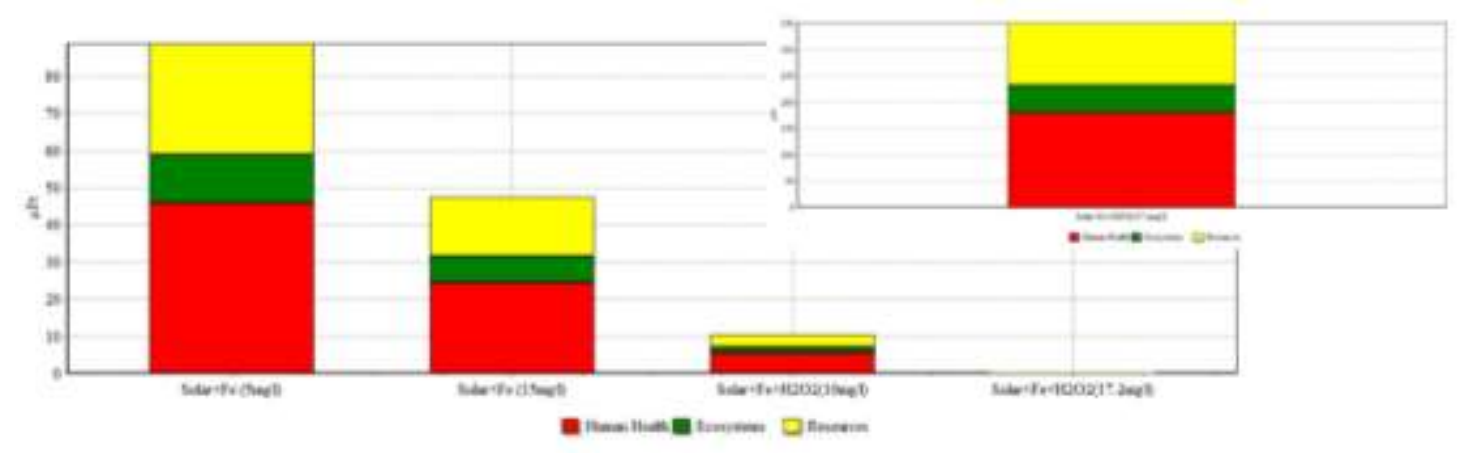

588

589 Figure 2.

590

591

592 


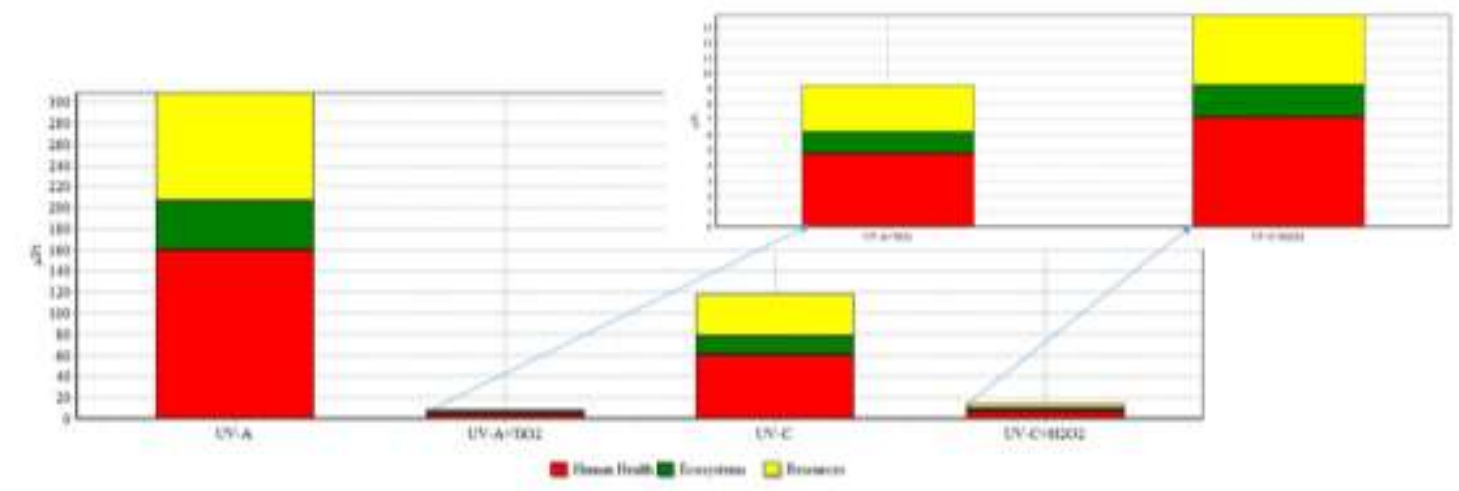

593

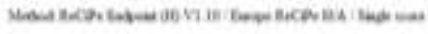

594 Figure 3.

595

596

597

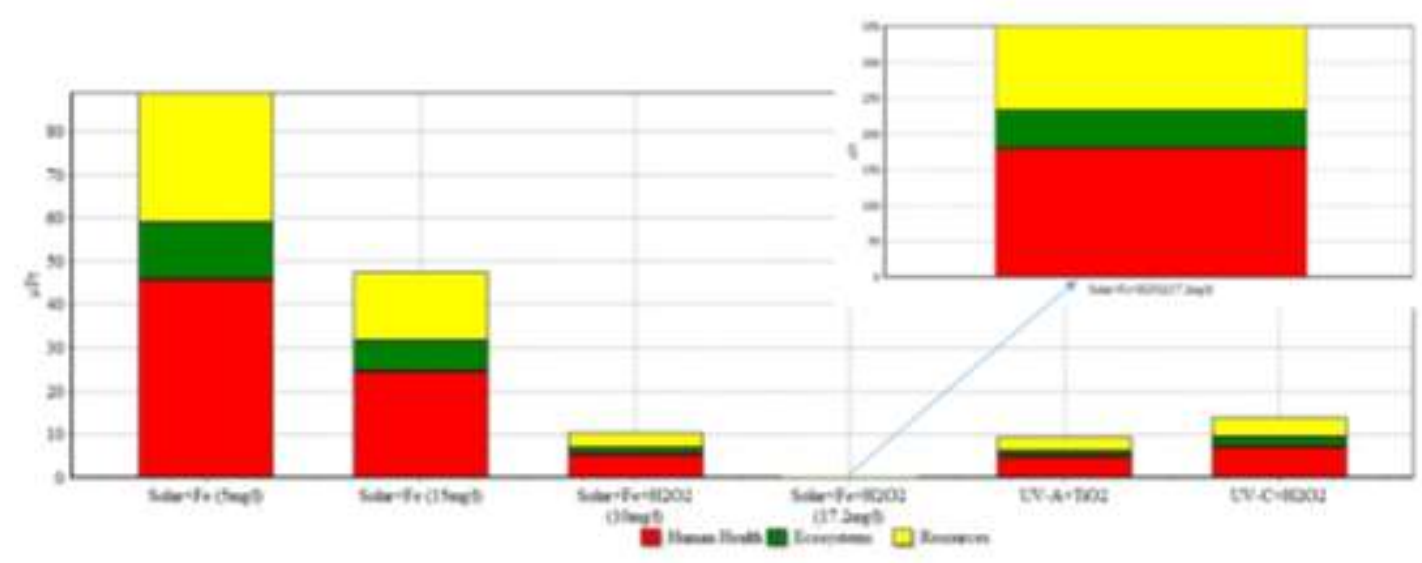

598

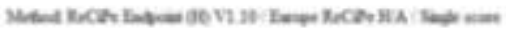

599 Figure 4.

600 